\title{
DAYA TERIMA KONSUMEN TERHADAP CITARASA ES KRIM BUAH KAWISTA (LIMONIA ACIDISSIMA)
}

\author{
Nur Manzalina Z.A ${ }^{1}$, Suryati Sufiat ${ }^{1}$, Rahmi Kamal ${ }^{1}$ \\ Program Studi Pendidikan Kesejahteraan Keluarga \\ Fakultas Keguruan dan Ilmu Pendidikan \\ Universitas Syiah Kuala Darussalam, Banda Aceh, Indonesia \\ nurmanzalina244@gmail.com
}

\begin{abstract}
Abstrak: Es krim buah kawista merupakan olahan susu dengan menambahkan kawista dan bahan lainnya kemudian dimixer sampai halus dan lembut. Tujuan penelitian ini adalah: (1) Menstandarisasikan resep es krim buah kawista melalui uji organoleptik (warna, aroma, tekstur, dan rasa), (2) mengetahui daya terima konsumen terhadap es krim buah kawista. Metode yang digunakan dalam penelitian ini adalah metode eksperimen dengan menggunakan pendekatan kuantitatif. Teknik pengumpulan data yang digunakan adalah uji pengamatan (Sensory Evaluation) yang dilakukan oleh 5 narasumber dan uji penerimaan (Acceptability Test) yang dilakukan oleh 30 panelis konsumen. Data dari uji pengamatan dianalisis dengan cara mengetahui nilai rata-rata (mean) yang diperoleh dari narasumber, sedangkan data dari uji penerimaan dianalisis dengan menggunakan analisis varian (anava) satu jalur yang diperoleh dari panelis konsumen. Apabila ada pengaruh signifkan maka dilanjutkan dengan uji $\operatorname{LSD}_{0,05}$. Berdasarkan hasil uji pengamatan oleh narasumber diketahui bahwa, es krim dengan penambahan buah kawista 100 gr (40\%) yang disukai adalah pada perlakuan kedua dengan kode NM024 ditinjau dari segi warna warna coklat muda dengan nilai rata-rata $(24,2)$, aroma sangat khas buah kawista dengan nilai rata-rata $(24,6)$, tekstur yang lembut dan halus dengan nilai rata-rata $(24,8)$ dan rasa yang manis dengan nilai rata-rata $(24,4)$. Berdasarkan hasil uji penerimaan panelis konsumen diketahui bahwa es krim dengan penambahan buah kawista 100 gr (40\%) yang disukai adalah pada perlakuan kedua dengan kode NM024 ditinjau segi warna warna coklat muda dengan nilai rata-rata $(4,23)$, aroma sangat khas buah kawista dengan nilai rata-rata $(4,16)$, tekstur yang lembut dan halus dengan nilai rata-rata $(4,26)$ dan rasa yang manis dengan nilai rata-rata $(4,33)$. Hipotesis membuktikan bahwa $\mathrm{H} 1$ dapat diterima, karena ada pengaruh penambahan buah kawista terhadap tingkat penerimaan kosumen baik ditinjau dari segi warna, aroma, tekstur, dan rasa.
\end{abstract}

Kata Kunci: Buah kawista, Es krim, Daya terima konsumen

\section{PENDAHULUAN}

Provinsi Aceh merupakan salah satu provinsi yang terletak diwilayah paling barat Indonesia. Daerah ini memiliki potensi besar dibidang pertanian dan perkebunan. Bidang pertanian menghasilkan beranekaragaman buah-buahan, salah satunya adalah buah kawista (Limonia acidissima). Buah kawista merupakan buah yang khas dengan aromamya, diwilayah aceh sering disebut dengan boh keumeukoh atau buah batok. Masyarakat Aceh mengolah buah kawista dijadikan sebagai bumbu rujak, atau ditambahkan dengan gula, garam, cabai rawit, dan dimakan begitu saja.

Es krim merupakan produk olahan susu yang dibuat dengan cara membekukan dan mencampur bahan baku secara bersama-sama. Menurut Suhardjito (2006:186), "Es krim merupakan salah satu jenis menu yang antara lain dapat dipergunakan sebagai makanan pencuci mulut, pelepas dahaga, dan yang lainnya. Dari zaman dahulu hingga sekarang es krim digemari oleh segala lapisan masyarakat, baik anak-anak, maupun 
orang dewasa. Es krim dapat dibuat dari yang sederhana maupun istimewa". Banyak es krim yang kita jumpai di pasar yaitu: es krim coklat, es krim vanilla, dan lain-lain. Seiring dengan berkembanganya pengetahuan dan teknologi masa kini, banyak es krim yang terbuat dari buah-buahan seperti es krim buah guava, es krim buah mangga, es krim buah naga, es krim buah semangka, es krim buah nanas, es krim greentea dan lain-lain.

Faktor-faktor yang mempengaruhi tekstur es krim adalah ukuran, bentuk dan distribusi dari kristal es dan partikel lainnya yang membentuk body es krim. Tekstur es krim yang disukai adalah halus, dan terasa lembut di mulut. Tekstur yang lembut pada es krim sangat dipengaruhi oleh komposisi campuran, pengolahan dan penyimpanan. Untuk memperoleh cita rasa kue bhoi subsitusi tepung labu kuning yang disukai konsumen, maka penelitian ini penting untuk dilakukan. Penelitian ini bertujuan menstandarisasikan dan mengetahui daya terima konsumen terhadap citarasa resep es krim buah kawista melalui uji organoleptik warna, aroma, tekstur, dan rasa.

Melihat kenyataan bahwa ketersediaan buah kawista yang tidak banyak diolah menjadi makanan dan minuman, dan juga kandungan gizi buah kawista yang tinggi, maka peneliti tertarik untuk melakukan penelitian mengenai es krim dengan penambahan buah kawista dengan judul penelitian "Daya Terima Konsumen Terhadap Citarasa Es Krim Buah Kawista (Limonia acidissima)".

Tujuan penelitian ini adalah sebagai berikut:
1. Menstandarisasikan resep es krim buah kawista melalui uji organoleptik (warna, aroma, tekstur, dan rasa).

2. Mengetahui daya terima konsumen terhadap citarasa es krim buah kawista melalui uji karakteristik organoleptik (warna, aroma, tekstur dan rasa).

Daya terima konsumen adalah tingkat kesukaan konsumen terhadap sesuatu. Daya terima konsumen yang dimaksud dalam penelitian ini adalah sikap konsumen terhadap warna, aroma, tekstur, dan rasa es krim buah kawista.

Resep standar (resep baku) merupakan takaran standar dalam penggunaan bahan-bahan dalam suatu pengolahan. Dari pendapat di atas dapat disimpulkan bahwa resep standar merupakan takaran baku yang disetujui dan diterima oleh masyarakat luas dalam proses pembuatan suatu makanan.

Citarasa adalah suatu cara pemilihan makanan yang harus dibedakan dari rasa makanan tersebut. Citarasa merupakan atribut makanan yang meliputi penampakan, bau, rasa, tekstur, dan suhu. Citarasa merupakan bentuk kerja sama dari kelima macam indera manusia, yakni perasa, penciuman, perabaan, penglihatan, dan pendengaran.

\begin{tabular}{lcr}
\multicolumn{4}{c}{ Warna adalah suatu kesan yang } \\
ditangkap oleh mata ketika \\
memandang suatu benda yang \\
memantulkan cahaya, seperti & warna \\
kecoklatan, kekuningan dan & chand \\
sebagainya. Warna yang dimaksud \\
dalam penelitian ini adalah warna
\end{tabular}


yang terlihat pada permukaan es krim dari buah kawista.

Aroma adalah reaksi dari makanan yang akan mempengaruhi konsumen sebelum konsumen menikmati makanan. Aroma yang dimaksud dalam penelitian ini adalah bau khas yang ditimbulkan oleh es krim dari buah kawista.

Tekstur adalah ukuran dan susunan (jaringan) yang berbentuk suatu benda, Beberapa sifat tekstur seperti kasar, halus, dan lembut dari permukaan bahan. Tekstur yang dimaksud dalam penelitian ini adalah halus atau lembutnya es krim dari buah kawista.

Rasa adalah sesuatu yang dirasakan didalam mulut yang merupakan perpaduan dari bau dan perasaan yang ditimbulkan dari suatu hidangan makanan dan minuman pada saat makan atau mencicipi makanan. Saat ini ada empat rasa dasar yang dapat dikenali oleh lidah yaitu, manis, asam, asin, dan pahit. Rasa yang dimaksud dalam penelitian ini adalah rasa manis yang ditimbulkan oleh es krim buah kawista.

\section{METODE PENELITIAN}

Penelitian ini tergolong dalam jenis penelitian eksperimen yang menggunakan pendekatan kuantitatif. Percobaan yang dilakukan dalam penelitian ini adalah penggunaan buah kawista dalam pembuatan es krim.

\section{Lokasi dan Waktu Penelitian}

Pelaksanaan penelitian uji organoleptik (warna, aroma, tekstur, dan rasa) dilakukan oleh narasumber dan konsumen. Penelitian ini dilakukan di Laboratorium Tata Boga Prodi Pendidikan Kesejahteraan
Keluarga Fakultas Keguruan dan Ilmu Pendidikan Universitas Syiah Kuala Darussalam Banda Aceh. Penelitian ini dilaksanakan pada bulan Agustus sampai dengan November 2018.

\section{Subjek dan Objek Penelitian}

Subjek dalam penelitian ini adalah 5 orang Dosen Tata Boga Fakultas Keguruan dan Ilmu Pendidikan Unsyiah, sebagai panelis terlatih (narasumber) dan 30 panelis konsumen mahasiswa mahasiswi FKIP Unsyiah dan konsumen umum.

Objek penelitian ini yaitu es krim dengan penambahan buah kawista.

Tabel 1. Bahan-bahan yang digunakan dalam pembuatan es krim buah kawista

\section{Bahan Penelitian}

\begin{tabular}{|c|c|c|}
\hline No. & Bahan & Kegunaan \\
\hline 1. & $\begin{array}{l}\text { Buah } \\
\text { Kawista }\end{array}$ & $\begin{array}{l}\text { Bahan baku pada } \\
\text { pembuatan es krim, } \\
\text { buah kawista yang } \\
\text { berkualitas bagus, } \\
\text { masak, dan baunya } \\
\text { yang harum. }\end{array}$ \\
\hline 2. & Susu & 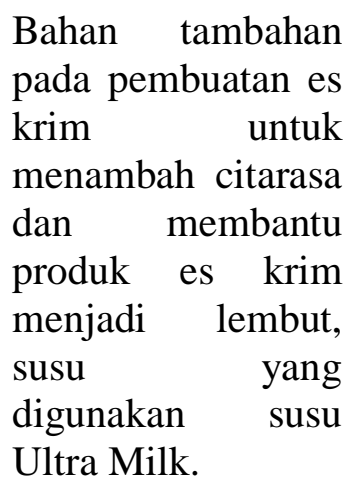 \\
\hline 3. & Santan & $\begin{array}{l}\text { Bahan tambahan } \\
\text { pada pembuatan es } \\
\text { krim, } \\
\text { memberikan rasa }\end{array}$ \\
\hline
\end{tabular}




\begin{tabular}{|c|c|c|}
\hline & & $\begin{array}{l}\text { lemak, santan yang } \\
\text { digunakan pati } \\
\text { santan. }\end{array}$ \\
\hline 4. & $\begin{array}{l}\text { Whippy } \\
\text { Cream }\end{array}$ & $\begin{array}{l}\text { Bahan tambahan } \\
\text { pada pembuatan es } \\
\text { krim, agar es krim } \\
\text { bertekstur lembut, } \\
\text { whippy cream yang } \\
\text { digunakan whippy } \\
\text { cream Haan. }\end{array}$ \\
\hline 5. & Gula & $\begin{array}{lr}\text { Bahan tambahan } \\
\text { pemanis } \\
\text { memberikan } \\
\text { kekentalan, pada } \\
\text { pembuatan es krim, } \\
\text { gula } \\
\text { digunakan gang } \\
\text { pasir. }\end{array}$ \\
\hline 6. & Garam & $\begin{array}{l}\text { Bahan tambahan } \\
\text { pada pembuatan es } \\
\text { krim agar terasa } \\
\text { gurih, garam yang } \\
\text { digunakan garam } \\
\text { dapur. }\end{array}$ \\
\hline 7. & Air & $\begin{array}{lr}\text { Air } & \text { sebagai } \\
\text { tambahan } & \text { yang } \\
\text { digunakan untuk } \\
\text { campuran whipped } \\
\text { cream, air yang } \\
\text { digunakan adalah } \\
\text { air es. }\end{array}$ \\
\hline
\end{tabular}

Tabel 2. Desain Percobaan Es Krim dengan Penambahan Buah Kawista dalam Ukuran Gram (gr)

\begin{tabular}{|c|l|c|c|c|}
\hline \multirow{2}{*}{ No } & Nama & \multicolumn{3}{|c|}{ Perlakuan (gr) } \\
\cline { 3 - 5 } & Bahan & NM & NM & NM \\
& & $\mathbf{0 2 2}$ & $\mathbf{0 2 3}$ & $\mathbf{0 2 4}$ \\
\hline 1. & Kawista & - & 50 & 100 \\
\hline 2. & Susu & 250 & 250 & 250 \\
\hline 3. & Santan & 250 & 250 & 250 \\
\hline
\end{tabular}

\begin{tabular}{|c|l|c|c|c|}
\hline 4. & $\begin{array}{l}\text { Whippy } \\
\text { cream }\end{array}$ & 30 & 30 & 30 \\
\hline 5. & Gula & 100 & 100 & 100 \\
\hline 6. & Garam & 10 & 10 & 10 \\
\hline 7. & Air es & 60 & 60 & 60 \\
\hline
\end{tabular}

Tabel 3. Desain Percobaan Es Krim dengan Penambahan Buah Kawista dalam Ukuran Persentase (\%)

\begin{tabular}{|c|l|c|c|c|}
\hline No & \multirow{2}{*}{$\begin{array}{l}\text { Nama } \\
\text { Bahan }\end{array}$} & \multicolumn{3}{|c|}{ Perlakuan (gr) } \\
\cline { 3 - 5 } & $\begin{array}{c}\text { NM } \\
\mathbf{0 2 2}\end{array}$ & $\begin{array}{c}\text { NM } \\
\mathbf{0 2 3}\end{array}$ & $\begin{array}{c}\text { NM } \\
\mathbf{0 2 4}\end{array}$ \\
\hline 1. & Kawista & - & 20 & 40 \\
\hline 2. & Susu & 100 & 100 & 100 \\
\hline 3. & Santan & 100 & 100 & 100 \\
\hline 4. & $\begin{array}{l}\text { Whippy } \\
\text { cream }\end{array}$ & 12 & 12 & 12 \\
\hline 5. & Gula & 40 & 40 & 40 \\
\hline 6. & Garam & 4 & 4 & 4 \\
\hline 7. & Air es & 24 & 24 & 24 \\
\hline
\end{tabular}

Tabel 4. Proses Pembuatan Es Krim dengan Penambahan Buah Kawista 100 Gram (40\%)

\begin{tabular}{|c|c|c|c|}
\hline No & Bahan & Jumlah & $\begin{array}{c}\text { Cara } \\
\text { Membuat }\end{array}$ \\
\hline 1. & $\begin{array}{l}\text { Buah } \\
\text { kawista }\end{array}$ & $100 \mathrm{gr}$ & $\begin{array}{l}\text { 1. Siapkan } \\
\text { semua }\end{array}$ \\
\hline 2. & Susu & $250 \mathrm{ml}$ & bahan. \\
\hline 3. & Santan & $250 \mathrm{ml}$ & \multirow{5}{*}{$\begin{array}{l}\text { 2. Saring } \\
\text { buah } \\
\text { kawista } \\
\text { agar } \\
\text { terpisah } \\
\text { dari } \\
\text { bijinya. }\end{array}$} \\
\hline 4. & $\begin{array}{l}\text { Whippy } \\
\text { cream }\end{array}$ & $30 \mathrm{gr}$ & \\
\hline 5. & Gula & $100 \mathrm{gr}$ & \\
\hline 6. & Garam & $10 \mathrm{gr}$ & \\
\hline 7. & Air es & $60 \mathrm{ml}$ & \\
\hline & & & $\begin{array}{l}\text { 3. Masukkan } \\
\text { santan, } \\
\text { susu, gula } \\
\text { dan garam }\end{array}$ \\
\hline
\end{tabular}


kedalam

satu wadah

lalu rebus

bahan

tersebut

hingga

mendidih

aduk rata,

angkat dan

dinginkan

sejenak.

4. Kocok

whippy

cream

dengan air

es hingga

menjadi

naik,

campurkan

rebusan

santan dan

susu tadi

tambahkan

daging

buah

kawista

yang sudah

disaring,

sambil

terus

dimixer.

5. Tempatkan adonan

kedalam

wadah, dan bekukan

adonan

kedalam

lemari

pendingin

(freezer)

selama 2-3

jam.

6. Keluarkan adonan dari (freezer) dan mixer kembali adonan es krim sampai

halus.

Masukkan

lagi

kedalam

(freezer).

7. Es krim

buah

kawista

siap

dikemas.

\section{HASIL PENELITIAN}

Hasil penelitian merupakan hasil dari pengumpulan dan penyusunan data penelitian yang dirangkum lebih detail sehingga terlihat lebih rinci dan sistematis.

Tabel 4. Hasil Uji Pengamatan II Terhadap Es Krim dengan Penambahan Buah Kawista 100 gr (40\%) pada Perlakuan Kedua NM024

\begin{tabular}{|c|c|c|c|c|c|c|}
\hline \multirow[t]{2}{*}{$\mathbf{N}$} & \multirow[t]{2}{*}{$\begin{array}{l}\text { Narasu } \\
\text { mber }\end{array}$} & \multicolumn{4}{|c|}{$\begin{array}{l}\text { Sifat } \\
\text { Organoleptik }\end{array}$} & \multirow{2}{*}{$\begin{array}{l}\text { Tota } \\
\text { l } \\
\text { Nila } \\
\text { i }\end{array}$} \\
\hline & & $\mathbf{W}$ & $\mathbf{A}$ & $\mathbf{T}$ & $\mathbf{R}$ & \\
\hline 1 & $\begin{array}{l}\text { Narasu } \\
\text { mber } 1\end{array}$ & 25 & 25 & 25 & $\begin{array}{c}10 \\
0\end{array}$ & 100 \\
\hline 2 & $\begin{array}{l}\text { Narasu } \\
\text { mber } 2\end{array}$ & 25 & 24 & 25 & 99 & 99 \\
\hline 3 & $\begin{array}{l}\text { Narasu } \\
\text { mber } 3\end{array}$ & 23 & 25 & 25 & 98 & 98 \\
\hline 4 & $\begin{array}{l}\text { Narasu } \\
\text { mber } 4\end{array}$ & 24 & 24 & 25 & 96 & 96 \\
\hline 5 & $\begin{array}{l}\text { Narasu } \\
\text { mber } 5\end{array}$ & 24 & 25 & 24 & 97 & 97 \\
\hline \multicolumn{2}{|c|}{ Total Nilai } & $\begin{array}{l}11 \\
2\end{array}$ & $\begin{array}{c}12 \\
1\end{array}$ & $\begin{array}{c}12 \\
3\end{array}$ & $\begin{array}{c}12 \\
4\end{array}$ & 490 \\
\hline \multicolumn{2}{|c|}{$\begin{array}{l}\text { Nilai rata- } \\
\text { rata }\end{array}$} & $\begin{array}{l}22 \\
, 4\end{array}$ & $\begin{array}{c}24, \\
2\end{array}$ & $\begin{array}{l}24 \\
, 6\end{array}$ & $\begin{array}{l}24 \\
, 8\end{array}$ & 98 \\
\hline
\end{tabular}

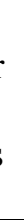




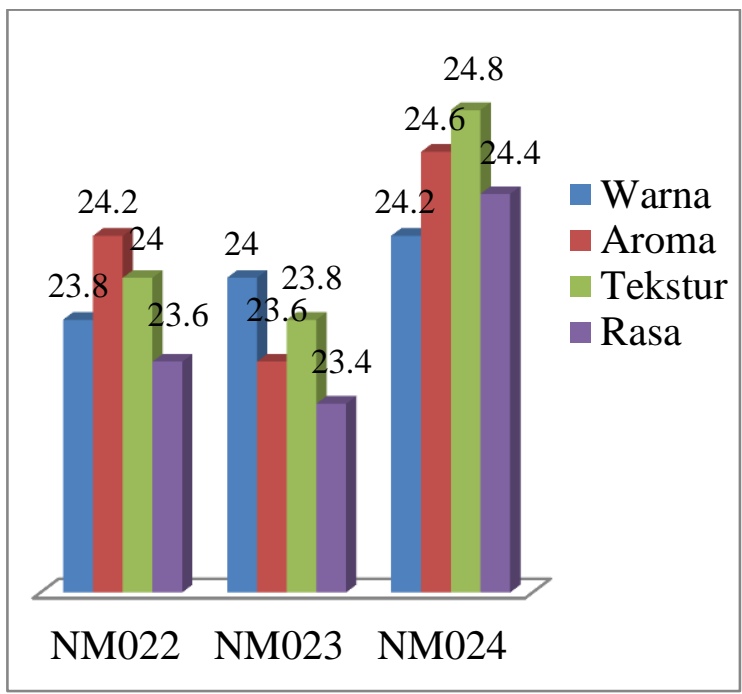

Berdasarkan hasil uji pengamatan oleh narasumber, maka dapat disimpulkan penilaian narasumber yang tertinggi terhadap karakteristik organoleptik (warna, aroma, tekstur, dan rasa) terdapat pada es krim buah kawista pengamatan kedua dengan kode NM024. Dengan alasan pengamatan kedua es krim dengan penambahan buah kawista 100 gr $(40 \%)$ ditinjau dari segi warna coklat muda dengan nilai rata-rata 24,2 , aroma sangat khas buah kawista dengan nilai rata-rata 23,6 , teksturnya yang lembut dan halus dengan nilai rata-rata 23,8 , dan rasanya yang manis dengan nilai rata-rata 24,4 .

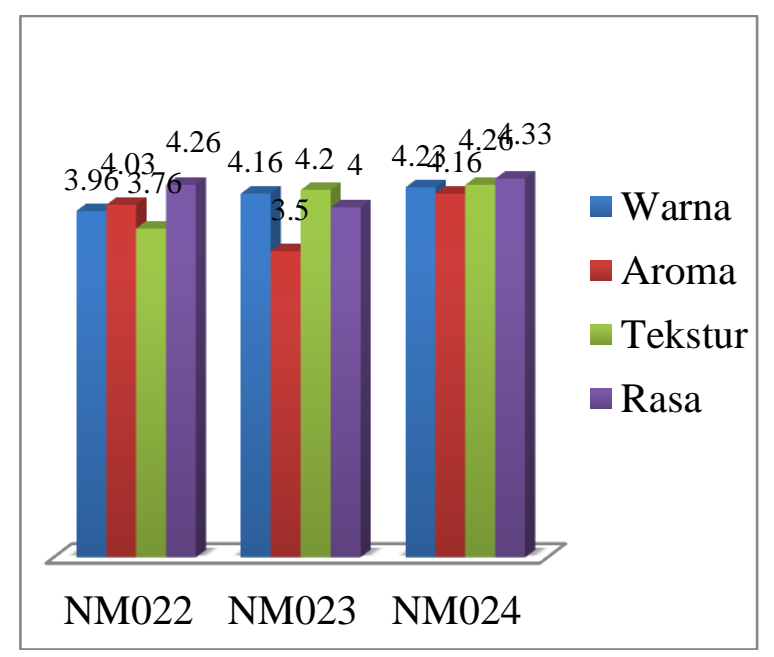

Berdasarkan hasil uji penerimaan oleh panelis konsumen maka dapat disimpulkan penilaian panelis konsumen yang tertinggi terhadap uji organoleptik ditinjau dari segi warna yang coklat muda dengan nilai rata-rata 4,23, aroma sangat khas buah kawista dengan nilai rata-rata 4,16 , tekstur yang lembut dan halus dengan nilai rata-rata 4,26 , dan rasa yang manis dengan nilai rata-rata 4,33 terdapat pada es krim dengan penambahan buah kawista $100 \mathrm{gr}$ (40\%) dengan kode NM024.

\section{KESIMPULAN}

Hasil dari uji pengamatan dan uji penerimaan organoleptik (warna, aroma, tekstur dan rasa) terhadap es krim dengan penambahan buah kawista 100 gr (40\%) yang dilakukan oleh narasumber menunjukkan bahwa narasumber lebih menyukai pada pengamatan kedua, dengan kode NM024 dari segi warna berwarna coklat muda dengan nilai rata-rata $(24,2)$, aroma sangat khas buah kawista dengan nilai rata-rata $(24,6)$, tekstur yang lembut dan halus dengan nilai rata-rata $(24,8)$ dan rasa yang manis dengan nilai rata-rata $(24,4)$, dan panelis konsumen lebih menyukai pada perlakuan kedua dengan kode NM024 dari segi warna berwarna coklat muda dengan nilai rata-rata $(4,23)$, aroma sangat khas buah kawista dengan nilai rata-rata $(4,16)$, tekstur yang lembut dan halus dengan nilai rata-rata $(4,23)$ dan rasa yang manis dengan nilai rata-rata $(4,33)$. 
DAFTAR PUSTAKA

Anonim. 2011. Syarat-syarat, Tata Cara Pengawasan dan Pemeriksaan Kualitas Susu Produksi dalam Negri. Jakarta: Manajemen Kesehatan Pemerahan.

Badan Standardisasi Nasional. 1995. SNI Es Krim 01-3713-1995. Jakarta: Badan Standardisasi Nasional.

Darmaprawira. 2002:32-34. "Pengertian Warna dan Tekstur". Jurnal (Online), (http://repo.isidps.ac.id/., diakses pada 11 Agustus 2018).

Dewi, Resvina. 2013. Bioaktivitas Buah Kawista (Limonia acidissima) Bima dan Penentuan Sidik Jarinya Menggunakan Kromatografi Lapis Tipis. Fakultas MIPA Institut Pertanian Bogor. Jurnal. (Online), (http://repository.ipb.ac.id/ diakses pada 24 Agustus 2018).

Fazri. 2008. Teori Kuliner Indonesia. Jakarta: PT. Trisula Adisakti.

FKIP Unsyiah. 2016. Pedoman Penulisan Skripsi. Banda Aceh: Fakultas Keguruan dan Ilmu Pendidikan Universitas Syiah Kuala.

Ilango,K., \& Chitra,V. 2009. Antidiabetic And Antioxidant Activity Of Limonia acidissima Linn.in alloxan induced rats. Der Pharma Lettre.

Marshall, R. T., and W. S. Arbuckle. 1996. Pages 59, 151-185, 263267, 319 in Ice Cream. 5th ed.
New York: International Thomson Publ.

Moehyi, S. 1992. Penyelenggaraan Makanan Institusi dan Jasa Boga. Jakarta: PT. Bharatara Niaga Media.

Padaga, M. Ch, dan M. E. Sawitri. 2005. Membuat Es Krim yang Sehat. Surabaya: Trubus Agrisarana.

Rahmawati Dwi Reni. 2012. Tingkat Penambahan Bahan Pengembang Pada Pembuatan Es Krim Instan Ditinjau Dari Mutu Organoleptik Dan Tingkat Kelarutan. Universitas Brawijaya Malang. Jurnal (Online), (http://fapet.ub.ac.id/., diakses pada 10 Agustus 2018).

Rini Soeroyo.1985. Buah-Buahan Langka. Jakarta: CV Indrapress/Si Kuncung.

Srihari, Endang. 2010. Pengaruh Penambahan Maltodekstrin Pada Pembuatan Santan Kelapa Bubuk. Jurnal Jurusan Teknik Kimia, (online), (http://jpa.ub.ac.id diakses pada 5 September 2018).

Soekarto. S.T. 1981. Metode Penelitian. Jakarta: Rineka Cipta

Suhardjito YB. 2006. Pastry dalam Perhotelan. Yogyakarta: CV Andi Offset.

Suharjo. 1989. Sosio Budaya Gizi Pusat Antar Universitas Pangan Dan Gizi. Bogor: IPB .

Sukamto LA. 1999. Morfogenesis Berbagai Eksplan Kawista (Limonia Acidissima) yang 
Ditumbuhkan Secara Kultur

[Prosiding]. Bogor (ID) : LIPI

Sukardi. 2003. Metode Penelitian

Eksperimen. Jakarta: Rineka Cipta.

Susilorini, T.E. dan M.E. Sawitri. 2007. Produk Olahan Susu. Jakatra: Penebar Swadaya.

U.S. Wheat Associates. 1981. Pedoman Pembuatan Roti dan Kue. Jakarta: Djambatan.

Winarno, F.G. 1997. Pangan Gizi Dan Teknologi Konsumen. Jakarta: Penerbit PT Gramedia Pustaka Utama.

Winiati Pudji Rahayu. 2001. Penuntun Pratikum Penilaian Organoleptik. Jurusan Teknologi Pangan dan Gizi Fakultas Teknologi Pertanian Institut Pertanian Bogor.

Wiyasha. 2006. Kimia Pangan dan Gizi. Jakarta: PT. Gramedia Pustaka Utama. 